\title{
Teaching through Dual Treatments and Its Influence on Students' Successful Mathematical Thinking
}

\author{
Assoc. Prof. Dr. Pranvera Gjoci \\ University of Elbasan, Albania, Faculty of Education Science \\ Department of Methodology of Teaching \\ Email: veragjoci@yahoo.com
}

Assoc. Prof. Dr. Svjetllana Kërënxhi

University of Elbasan, Albania, Faculty of Natural Sciences,

Department of Mathematics

Email: skerenxhiel@yahoo.com

\section{Doi:10.5901/jesr.2014.v4n6p191}

\begin{abstract}
There are some concepts, processes and other mathematical situations that are included in mathematics textbooks of the elementary education, and they exist simultaneously with their dual concept, process and dual situation. In teaching process these dualities should be treated always together, as they exist in our world. In order to understand how this is realized, in this paper is described teaching of elementary mathematics through dual treatments and in details, the implementation of dual treatments in the first grade of elementary education. The results of the study with 53 students of the first grade of elementary education, after the implementation of teaching through dual treatments showed a crucial statistic effect on students' successful mathematical thinking.
\end{abstract}

Keywords: duality, dual treatment, elementary education, teaching mathematics, mathematical thinking

\section{Introduction}

The phenomenon of duality in the teaching process has got the attention of many scholars. For example, Kessels, Korthagen, Lagerwerf, who have studied the effectiveness of teacher's education, as starting point of their models presented (Korthagen \& Lagerwerf, 1996; Korthagen \& Kessels, 1999; Korthagen, 2010) have the duality 'teacher learning - teacher behaviour'. Gray and Tall (1994) studied the advanced mathematic thought of the students (7-12 years old) taking into consideration the duality between the process to carry out a mathematical task and the concept to be mentally manipulated as part of a wider mental schema. Yastrebov (2001) after describing the dual properties that characterize mathematics, emphasise the importance of including these dual properties in the process of the study of mathematics. Duality existing in mathematics was reflected in teaching of mathematical special fields (Artstein-Avidan \& Milman, 2007; Gao, 2000; Yastrebov, Menshikova \& Yepifanova, 2006). Through examples from algebra, solid geometry, trigonometry and mathematical analysis was presented the reflection of duality in teaching of its mathematical special fields and note that the notion of duality is one of the central concepts both in geometry and in analysis. Based on these experiences and the presence of duality in mathematical textbooks, which are rich in dual concepts, dual processes, dual properties, dual affirmation, dual theorems and other dual mathematical situations, we have structured teaching through dual treatments.

In this article it is introduced the study about the implementation of dual treatments in teaching of mathematics in the first grade of elementary education. The purpose of the study was to examine the effect of teaching through dual treatments on students' successful mathematical thinking and to understand if we can move forward to the phase of a wider study implementing the new method of teaching on a great number of students. The students' successful mathematical thinking is identified as realization of different viewpoints of mathematical situations during learning process to appropriate the standards and values embodied in the discipline of mathematics. The students' transition in the levels of successful thinking is reached through the improvement of the structure of knowledge enriching the mathematical information with elements of dual viewpoint. 


\section{Teaching through Dual Treatments}

Dual treatment is one of the directions of our research in the teaching of mathematics. During academic year 2009-2010, a study was conducted in ten classes of elementary education of 9-years schools. To the study were subservient ten teachers and 342 students who were distributed in ten classes: in two 1st grades, in two 2nd grades, in two 3rd grades, in two 4th grades and in two 5th grades. In collaboration with the teachers were chosen a whole number of concepts, exercises and mathematical problems which allowed dual treatment. The selected models were implemented in classes of mathematics to develop to the students the ability to see issues from dual point of view (Gjoci \& Kërënxhi, 2010). Then the research was concentrated in the first grade of elementary education. We will describe below the way of implementation of dual treatments and its effects in the mathematics teaching.

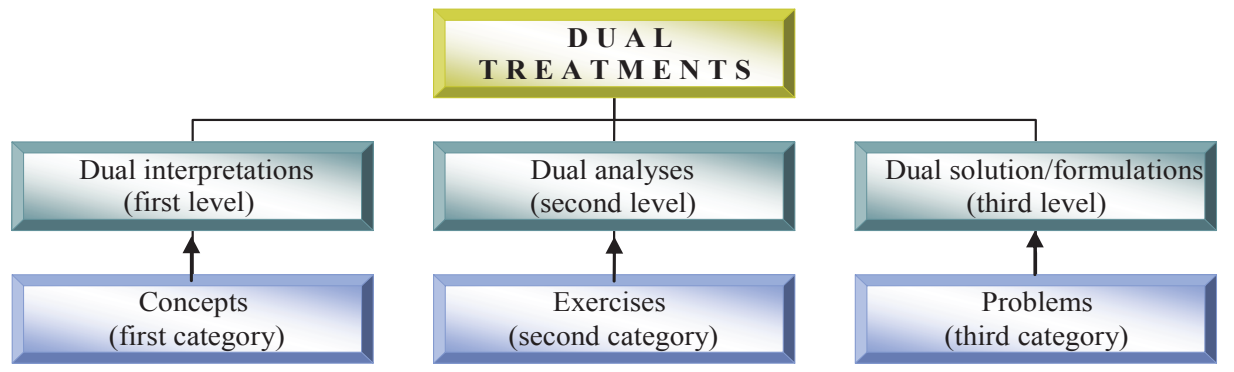

Fig. 1 Teaching through dual treatments

By dual treatment in mathematics of elementary education, we mean the dual interpretation, dual analysis, dual solution and dual formulation of the concept, exercise and problem, that carries a dual nature (Kërënxhi \& Gjoci, 2013). Teaching through dual treatments, which we visualize in Fig. 1, was realized by the teacher of experimental group about three categories, which are included in the mathematics program and textbooks.

In the $1^{\text {st }}$ category those concepts that accept dual interpretation were included. By dual interpretation we understand the process according to which the concept is interpreted with its dual aspect. Dual interpretations of the simple concepts are the first level in our model of teaching through dual treatments, Fig. 1. Dual treatments of the first level were applied by the teacher of experimental group starting from the first topics of teaching mathematics of the first grade, where the dual concepts are present. The meanings 'inside-outside' were the first dual meanings which the teacher interpreted in duality. They were interpreted in duality for the first time in the four lesson of the first unit "Concepts inside, outside". The teacher made sure the students to become familiar with these meanings and individualized elements of set in its internal area. The assimilation of these meanings is also important for the fact that becoming familiar with them precedes the topic on the association one by one and the topic on other dual meanings of 'more thanless than'. The meanings 'more than-less than' are some of the most important meanings pertaining to the understanding of the number directly related to it. They were interpreted in duality in the sixth lesson of the first unit "Relations: more than, less than, as many as", which is covered in the second week of the school program. By using the method of accompanying one by one the elements of both sets the students can make the comparison of the sets, to come to the conclusion: which has more elements and which has fewer elements. By the sixth lesson of the second unit, which is taught in the third week of the teaching program of mathematics, the markings $>,<$ were interpreted in duality for the first time; while in the seventh lesson of the second unit, "The comparison of numbers 1 to 4 . The marks $>$ and <", this two markings link two numbers by forming an inequality. The teacher often asked such questions as "what do we have more" and for the same model of exercise she asked "what do we have less?" In the seventh lesson of the second unit the teacher asked students to answer the questions: "what do we have more?", "what do we have less?", "which number is bigger?", "which number is smaller?". 


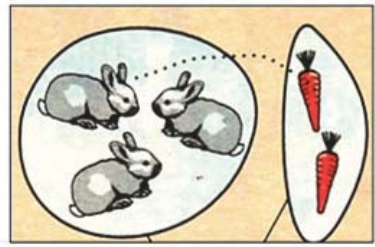

Fig.2 The comparison of sets and numbers

In order to make clear the differences of teaching through dual treatments and traditional teaching we show in a detailed the teaching to understand quantities and comparison of numbers. The two teachers, the teacher of control group (CG) and the teacher of experimental group (EG) proceed the lesson: "The comparison of numbers 1 to 4 . The marks > and <" (Dedej et al., 2010, p. 18). At the beginning both teachers proceeded equally. Showing the Figure 2, the teachers ask from the students to associate the rabbits with the carrots one by one.

The teacher of CG/EG: -What are there more, rabbits or carrots?

The students: - There are more rabbits than carrots.

The teacher of CG/EG: -How many rabbits are there?

The students: - There are tree rabbits. The teacher writes on the blackboard the number 3.

The teacher of CG/EG: -How many carrots are there?

The students: There are two carrots. The teacher writes on the blackboard the number 2.

The teacher of CG/EG: -Which number is bigger, the number three or the number two?

The students: The number three.

The teacher of CG/EG completes: -The number three is bigger than the number two, so we write $3>2$.

The teacher of experimental group (EG) continued the discussion:

The teacher of EG: -What do we have less, rabbits or carrots?

The students: -There are fewer carrots than rabbits.

The teacher of EG: -Which number is smaller, the number three or the number two?

The students: -Number two.

The teacher completes: -The number two is smaller than the number three, so we write $2<3$.

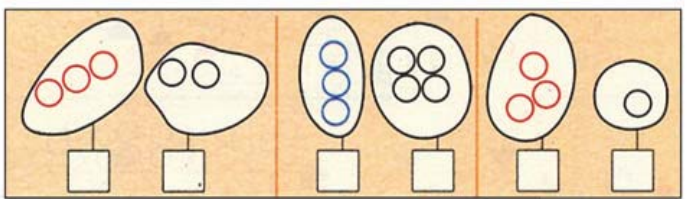

Fig.3 The comparison of sets and numbers

The differences between two strategies of teaching were seen at the end of the lecture when the students fulfilled the exercises of the Figure 3 . The students of experimental group write six inequalities: $3>2,2<3 ; 3<4,4>3 ; 3>1,1<3$, while the students of control group write only three: $3>2,3<4,3>1$, after the comparison of quantities.

After several classes, the students of experimental group gained the special ability of seeing at the same time both relations: 'greater than', 'less than'. This means that if the students are given an inequality for example $3>2$, both relations ' 3 is greater than 2 ' and ' 2 is less than 3 ' should come to their mind.

The length meaning is one of the main meanings that are linked directly with the distance meaning. The term of length in mathematics serves to characterize the segment and exactly its measure. The experimenting teacher interpreted comparison of lengths through the meanings 'longer than', 'shorter than' according to our recommendation.

The meaning of length is one of the main meanings that are linked directly with the meaning for distance. The term of length in mathematics serves to characterize the segment and exactly its measure. The teacher of EG interpreted the meanings 'longer than-shorter than' in duality, using a lot of examples of comparison. For every example the teacher of EG asked the students to answer not only to the question: "which is longer?" but also to the question: "which is shorter?" In Table 1 there are showed in a detailed way the differences of teaching through dual treatments from traditional teaching about the lengths meaning. 
Table 1: Comparison of lengths

Traditional teaching
The teachers of CG taught the meaning 'longer
than' shows the students two pencils with different
length and different colour as the Figure 4 . The
teachers ask the students: which is longer?
The teachers of CG taught the meaning 'shorter
than' shows the students two another pencils with
different length and different colour (blue, red) as
the Figure 5 . The teachers ask the students: which is
longer?
Teaching continued with many examples comparing
each time two objects. Students showed only one of
the cases: it is 'longer than' or it is 'shorter than' for
each couple.

Teaching through dual treatments

The teacher of EG taught in duality the opposite meaning 'longer than - shorter than'. The teachers show the students two pencils with different length and different colour as the Figure 6 .

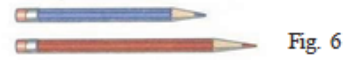

The teacher of EG: -Which pencil is longer?

The students: - The red pencil is longer.

The teacher of EG fulfilled: -The red pencil is longer than the blue pencil.

The teacher of EG: -Which pencil is shorter?

The students: -The blue pencil is shorter than the red pencil.

Teaching continued with many examples comparing each time two objects. The teacher of EG asked the students to show which is 'longer than' and which is 'shorter than' for each couple.

So the teacher of experimental group insisted that for the students should be made clear the fact that when we say the red pencil is longer than the blue one, at the same time the blue pencil is shorter than the red one.

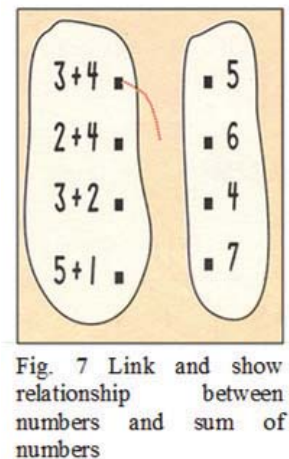

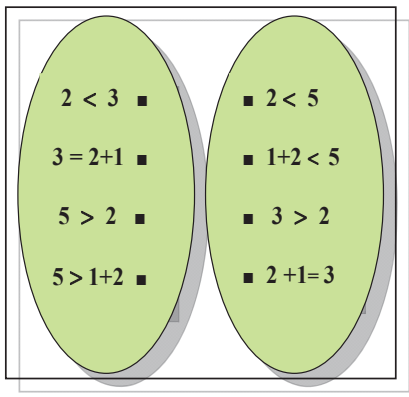

Fig. 8 Link and analyse the relationship between them

In the $2^{\text {nd }}$ category there were given simple applicative exercises that are included in the mathematical program. They were treated in two different points of view or according to us, they accept the dual analysis. The dual analyses of simple applicative exercises are the second level in our model of teaching through dual treatments, Fig.1. The dual treatments of the second level were applied by the teacher of experimental group starting with very simple exercises after the quarter of the mathematical program of the $1^{\text {st }}$ grade had been developed. In the fifth lesson of the unit five "Addition with the sum 6 in number line" the teacher analyzes in duality for the first time: $1+5=6$ and $6=1+5 ; 2+4=6$ and $6=2+4$. In the six lesson of the unit eight "Applications", after the students have linked the corresponding couples of the Figure 7, the students acknowledged that 3 plus 4 is equal to 7 and 7 is equal to 3 plus $4 ; 2+4=6$ and $6=2+4 ; 3+2=5$ and $5=3+2 ; 5+1=6$ and $6=5+1$. Such exercises lead to understanding of the equation $a+b=c$ as the fact that the amount of numbers $a+b$ is equal to the number $\mathrm{c}$, while number $\mathrm{c}$ can be understood as the sum of two terms $a$ and $b$. A model that was used by the teacher in class to reach the level on students' successful mathematical thinking was the exercise shown in Figure 8.

In the $3^{\text {rd }}$ category there were included problems with the request for the dual solution and dual formulation. The problems included in the third category have creative character and should have a high degree of the logic formulation of the student. The student should be able to give different solution for these problems, to build different schemas for their solving and to give the dual problem of the given problem. This category is the third level in our model of teaching though dual treatments Fig.1.

One example of dual solving applied by the teacher of experimental group is: Jenny bought 6 notebooks. Emma 
bought 9 notebooks. How many notebooks bought both girls together? Solve the problem in two ways. After working in groups students gave the solutions: $6+9=15=(6+4)+5=15$ and $6+9=(6+6)+3=15$.

One example of dual formulation applied by the teacher of experimental group is: The teacher created in the class a store with flowers and put as a seller one of the students. Then she invites Anna and Mary. The teacher told them to buy flowers as a gift for their mother. Anna bought 6 flowers meanwhile Mary bought 9 flowers. The teacher asked the students to solve this problem: Anna bought 6 flowers meanwhile Mary bought 9 flowers. Which girl bought more flowers? How many flowers more? The students solved this problem $(9-6=3)$ and answered it. Teacher asked the questions: Which girl bought fewer flowers? How many flowers less? Students solved this problem $(9-6=3)$ and answered it. In both models the problems were solved in the same way, despite from different formulations of the questions. Teacher noted this fact by the help of her students.

Dual formulation includes the initial problem and the opposite problem or the dual problem. In this level we evaluate especially the training of students for the dual formulation of the problem and understanding that the dual problem differentiates from the opposite problem because in the dual problem, the solution doesn't change but only the formulation does. We can give the dual problem as linked to the initial grant, and as linked to its opposite problem. In Table 2 there is shown the example of a problem; its opposite; the dual problem of the initial problem; the dual problem of the opposite problem.

Table 2: Problem and dual formulation

1) Initial problem

The first day students planted 30 trees. The second day they planted 10 trees more than the first day. How many trees did they plant the second day?

Solution:

$30+10=40$ trees

3) Dual problem of given problem

The first day students planted 30 trees. This amount was 10 trees less than trees, which are planted the second day. How many trees did they plant the second day? Solution:

$30+10=40$ trees

\section{2) Opposite problem}

The first day students planted some trees, the second day they planted 10 trees more than the first day. How many trees did they plant the first day if the second day they planted 40 trees? Solution:

$40-10=30$ trees

\section{4) Dual problem of opposite problem}

The first day students planted 10 trees less than the second day. How many trees did they plant the first day if the second day they planted 40 trees?

Solution:

$40-10=30$ trees

In the example above the problems (1), (3) and (2), (4) will be called reciprocally dual. A fundamental characteristic of reciprocally dual problems is that they change their shapes from the outside, from the wording, but their solution is the same. The reciprocally dual problems express in two different ways the same mathematical situation. After a careful practice in relation with the dual formulation of problem, teacher can apply exercises with combined requests with the advanced students. These requirements include mixed reviews, problem solving and application. In Table 3 there are shown the examples of exercises with combined requests. Such exercises help on students' successful mathematical thinking.

Table 3: Exercises with combined requests

\section{Exercise 1}

Brian has 6 cars. Robert has 2 cars more than Brian. How many cars do they both have? Use the model to solve the problem.

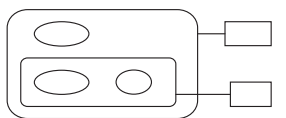

\section{Exercise 2}

Alex has 10 pencils. Rey has 3 pencils less than Alex. How many pencils do they both have? Use the model to solve the problem.

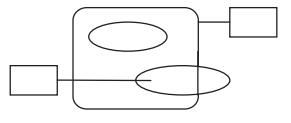

Think!

1) Which of the problems is solved in another way? If you can, show the other solution.

2) Which of the problems we can formulate differently? If you can, formulate it differently.

To emphasize the effectiveness that has caused the implementation of teaching through dual treatments in mathematics we will mention the words of the experimental teacher: I am now quite happy with myself and with my students. We have 
clear perception of the dual treatment and can discuss it together freely for new opportunities. We try to apply it not only in mathematics but also in other subjects.

The dual treatments, allow the successful students to be flexible in thinking, moving in between both viewpoints, thus creating the possibility for the students to understand the existence at the opposite realities upon the same scene. If the teacher of the elementary school teaches the students to use a mental structure based on dual treatments, then such abilities come out from the students, that the students at the same time can see both realities of the same view. A student with these reflexes will be always successful in mathematics.

\section{Effect of the Method on Student's Successful Mathematical Thinking}

The research questions which guided the empirical work of the study were:

1. What is the effect on students' successful mathematical thinking after implementation of teaching through dual treatments?

2. Are there differences between genders on successful mathematical thinking after implementation of teaching through dual treatments?

\subsection{Method}

\subsubsection{Research Design}

A quasi-experimental design was used in this study. The most commonly used quasi-experimental design is the nonequivalent groups design (NEGD). In the NEGD, most often are used intact groups that are thought to be similar as the treatment and control groups. In education, we might pick two comparable classrooms (Trochim, 2001).

\subsubsection{Participants}

In the study were included 53 students (29M, 24F) of the first grade of two 9-years schools. The two comparable classes formed two study groups: experimental group (27 students, 14M, 13F) and control group (26 students, 15M, 11F). Students were of age 6-7 years old. The teachers, who taught in these classes, had a college degree, with a relatively long teaching experience (more than 20 years of teaching) with the same level of qualification. The teachers implemented the curricula in these classes approved by the Ministry of Education and Science. Teaching of mathematics was carried out using the textbook "Matematika 1" by Dedej et al. (2010). The equipment and methods used by the teachers were the same. The students had the same conditions for teaching. We tried for the difference between the two groups to be as small as possible, except for the way of teaching topics. During this study, in one group the dual treatments were implemented, whereas in the other group they were not.

\subsubsection{Instruments and procedure}

In the experimental group the teaching through dual treatments during teaching of mathematics was implemented whereas and the control group used the traditional teaching method. In order to evaluate and analyze the influence of the model of teaching through dual treatments in the achievements of students in mathematics a pre-test and post-test were used for experimental and control group. Students in both groups were tested before and after the implementation of the model.

The post-test was based in the most important issues of school curriculum. Questions or exercises of the post-test were grouped into 8 categories: 1) The comparison between the two sets had 6 items, 2) The comparison of numbers had 5 items, 3) Addition and subtraction of numbers up to 20 using different methods of addition had 6 items, 4) The addition of numbers up to 100, without regrouping into the tens column had 4 items, 5) Solution of the problematic situation expressed in figure had 3 items, 6) Solution of the problematic situation expressed in words had 3 items, 7) Solution of equations with proofs, putting instead of the unknown, numbers selected from a finite set, had 4 items, 8) Solution with proofs of the inequalities had 5 items. In order to evaluate the students' successful mathematical thinking the exercises of the post-test were accompanied with requests for dual interpretations, analysis, solutions or formulations setting the total value of points in 51. The post-test was conducted in the third week of May. Data was analyzed using SPSS 17.0 


\subsection{Results}

One t-test for two independent samples was used to detect any significant differences between the experimental group and the control group on the pre-test scores. No significant violation was found. The analyses revealed no statistically significant differences in prior achievement of the students in mathematics [t(51)=-.705, $p=.484]$.

Appropriate parametric tests ANCOVA were used to detect any significant differences between the experimental group and the control group. ANCOVA has four assumptions: Normality, equality of variances, homogeneity of slopes, and independency of scores on the dependent variable. For normality's assumption the p-value .052 and .109 from Shapiro-Wilk Test are both greater than an alpha level of 0.05 which imply that it is acceptable to assume that the weight distributions for control and experimental populations are both normal. The skewness and kurtosis values were in approximately acceptable range for a normal distribution. Levene's Test of Equality was used to determine the equality of variance assumption. Levene's Test shows that error variance for successful mathematical thinking $F(1,51)=.002$, $p=.963$, is equal across groups. The third assumption that was checked before conducting the ANCOVA was homogeneity-of-slopes. This test evaluated if there was an interaction between the covariate, pre-test and the independent variable. As it can be seen the interaction Group*Pre-test was not significant, $F(1,49)=1.499, p=.227$. For the last assumption, independency of scores was examined. Teachers in the classes were requested to observe each student in order to validate this assumption. All students who participated did their tests by themselves. The evaluation of the answers was done by both teachers in order to be closer to the real evaluation of the students.

The results from an ANCOVA analysis include data on the post-test successful mathematical thinking for the experimental and control groups after using the prior mathematics achievement scores as covariates.

\subsubsection{Effect of teaching through dual treatments on students' successful mathematical thinking}

The ANCOVA measures were conducted to determine any significant differences between the experimental and control group mean scores in post-test of the students' successful mathematical thinking, after using the achievement of pre-test as covariates. Results indicated a statistically significant effect for experimental group, $F(1,50)=7.008$ and $p=.011$ for successful mathematical thinking. These results indicate that the teaching through dual treatments influence on the students' successful mathematical thinking. The difference between groups in the mean scores, $44.37(S D=6.37)$ for experimental group and 41.08 (SD=6.63) for control group, indicates that dual treatments, so the interpretations, analysis and solutions about the dual situations are understood and applied from the students.

\subsubsection{Differences between boys and girls genders on successful mathematical thinking after implementation of teaching through dual treatments}

A t-test for independent samples was administered to the post-test scores to determine whether there was any statistical significance between boys and girls. The $t-v a l u e ~(t=-.841, p<.408)$ is not significant at 0.05 significance. The results have shown that there is no significant difference between girls and boys in successful mathematical thinking after implementation of teaching through dual treatments. So the dual treatments have equally affected on boys and girls and the gender factor does not have its effectiveness on successful mathematical thinking.

\section{Discussions}

The idea about the possibility of inclusion of dual treatments in the mathematics of elementary education came out as the result of the knowledge that we have about the process of teaching in the elementary education and the knowledge that we have about the mathematics and dual relationships which characterize mathematics.

Up to now, our study shows that the inclusion of dual treatments in the teaching process of mathematics in the primary education influences a lot on the level of assimilation of knowledge of this subject, helping the students towards the creation of integrating perceptions and the further promotion of critical thinking. Bailin et al. (1999) argue that critical thinking instruction at the elementary grade levels can include teaching students to be willing to see things from another's perspective, while Willingham (2007) note seeing both sides of an issue. Psychological studies have often identified the special ability of the human brain to single out the objects in a periodical way, once in a logical plan, another time in another logical plan. In order to demonstrate this ability of the human brain Fisher (2005), Pettijohn (1996), use the gestalt figures. Just like Fisher (2005) tries to enable the students through the gestalt figures we through the dual 
treatments, aim for the students' flexibility in thinking and to understand the existence of the opposite realities upon the same scene. If the teacher of the $1^{\text {st }}$ grade teaches the students to use a mental structure based on dual treatments, then such abilities come out from the students' meaning, that the students can see both realities of the same view at the same time. These abilities help the student to become complete with the mental reflexes of the dual perceptions and integrative perceptions. The formation of the students with integrative perceptions is fully possible to be achieved, due to the dual nature of mathematics Gao (2000). The pedagogical benefits from the use of teaching through dual treatments are mostly in the critical way of solving problems and exercises, generating new ideas during their dual treatments and flexibility of thinking. A student with the reflexes of integrative perceptions will always be successful in mathematics (Gjoci \& Kërënxhi, 2013).

Teaching through dual treatments was applied in mathematics of elementary education, but we think, that similarly there exist all possibilities that they can be a method of thinking and reasoning for students in other subjects. When we study mathematics, biology, language, literature or any other subject, the students can be encouraged to think and study in an active manner and can further apply what they have learned through dual viewpoint.

Besides the achievements up to now in teaching through dual treatments there are still issues that should be further explored. In order to have full details we will concentrate our study in a broader empirical base. For this we should collect, process and analyze statistical data gathered from an experiment with the model in a bigger group of teachers and students. The study will start from the 1-st grade of elementary education and will continue step by step to higher grades. Such a study, that will give a detailed answer to the efficacy of teaching through dual treatments, will be the focus of our study in the future.

\section{References}

Artstein-Avidan, Sh., \& Milman, V. (2007). A characterization of the concept of duality. Electronic Research Announcements in Mathematical Sciences, 14, 42-59.

Bailin, S., Case, R., Coombs, J. R., \& Daniels, L. B. (1999). Conceptualizing critical thinking. Journal of Curriculum Studies, 31(3), 285302.

Dedej, K., Spahiu, E., \& Konçi, Z. (2010). Matematika 1: për klasën e parë të shkollës 9-vjeçare. Tiranë: SHBLSH e Re.

Fisher, R. (2005). Teaching children to think, (2nd ed.). Cheltenban: Nelson Thornes.

Gao, D. Y. (2000). Duality principles in nonconvex systems: Theory, Methods and Applications. Boston/Dordrecht/London: Kluwer Academic Publishers.

Gray, E. M., \& Tall, D. O. (1994). Duality, ambiguity, and flexibility: A proceptual view of simple arithmetic. Journal for Research in mathematics education, 26(2), 115-141.

Gjoci, P., \& Kërënxhi, S. (2010). Dual interpretations in primary education mathematics as aspect of critical thinking of students. Odgojne Znanosti - Educational sciences. 2(20), 413-426.

Gjoci, P., \& Kërënxhi, S. (2013). Duality and the importance of dual treatments' inclusion in teaching. Journal of Education \& Social Research, 7(3), 631- 638.

Kërënxhi, S., \& Gjoci, P. (2013). A new methodical treatment for math teaching and its effect on math learning. Journal of Education \& Social Research, 7(3), 662- 670.

Korthagen, F. A. J. (2010). Situated learning theory and the pedagogy of teacher education: Towards an integrative view of teacher behavior and teacher learning. Teaching and Teacher Education, 26, .98-106.

Korthagen, F. A. J., \& Kessels, J. P. A. M. (1999). Linking theory and practice: changing the pedagogy of teacher education. Educational Researcher, 28(4), 4-17.

Korthagen, F. A. J., \& Lagerwerf, B. (1996). Reframing the relationship between teacher thinking and teacher behaviour: levels in learning about teaching. Teachers and Teaching: Theory and Practice, 2(2), 161-190.

Pettijohn, T. F. (1996). Psikologjia - Një hyrje koncize (2nd ed.). (in albanian) Tiranë: Lilo.

Trochim, W. M. K. (2001). The research methods knowledge base, (2nd ed.). Cincinnati, OH: Atomic Dog Publishing.

Willingham, D. T. (2007). Critical thinking: Why is it so hard to teach? American Educator, 8-19.

Yastrebov, A. V. (2001). Dualistic properties of mathematics and their reflection in the process of teaching. Yaroslavl Pedagogical Gazette, (in Russian) 1, 48-53.

Yastrebov, A. V., Menshikova, N. A., \& Yepifanova, N. M. (2006). Identifying dualistic properties of science in the process of teaching in elementary mathematics. Yaroslavl Pedagogical Gazette, (in Russian) 4, 87-93. 